\title{
Underground Vegetables: Safe Handling Practices for Consumers ${ }^{1}$
}

\section{Amy Simonne ${ }^{2}$}

Underground vegetables are grown under the soil. They typically are exposed to the microorganisms that are found in the soil. Did you know that fresh produce can cause foodborne illness if not handled properly? This is especially true during the summer months when risk for all foodborne illness increases. Here are steps that you can take to reduce your risk of foodborne illness from underground

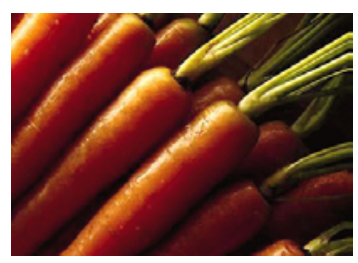
vegetables.

\section{Where You Shop:}

- Buy underground vegetables that are not bruised or damaged.

- If you buy vegetables in fresh-cut form, be sure they are refrigerated or surrounded by ice.

\section{At Home:}

- Fresh underground vegetables that need refrigeration (carrots, beets) should be refrigerated promptly. Sweet potatoes or Irish potatoes do not need refrigeration.

- All underground vegetables should be refrigerated within two hours of peeling or cutting.
- Leftover cut underground vegetables should be discarded after two hours at room temperature.

\section{During Preparation}

- Wash hands with hot, soapy water before and after:

- handling fresh produce

- handling raw meat, poultry, or seafood

- using the bathroom

- changing diapers

- handling pets

- Wash underground vegetables with cool running water just before preparing or eating. Don't use soap or detergents.

1. This publication is FCS8746, one of a series of the Department of Family, Youth and Community Sciences, Florida Cooperative Extension Service, IFAS, University of Florida. Publication date: November 2002. Please visit the EDIS Web site at http://edis.ifas.ufl.edu

2. Amy Simonne, Ph.D., assistant professor, Department of Family, Youth and Community Sciences, Cooperative Extension Service, IFAS, University of Florida, Gainesville, 32611. Reviewed by Glenda L. Warren, associate professor, M.S. Department of Family, Youth and Community Sciences, and Jeffrey K. Brecht, Ph.D., professor, Department of Horticultural Science, IFAS, University of Florida, Gainesville, 32611. 
- Scrub underground produce, such as potatoes and carrots, with a clean produce brush. Rinse with cool running water.

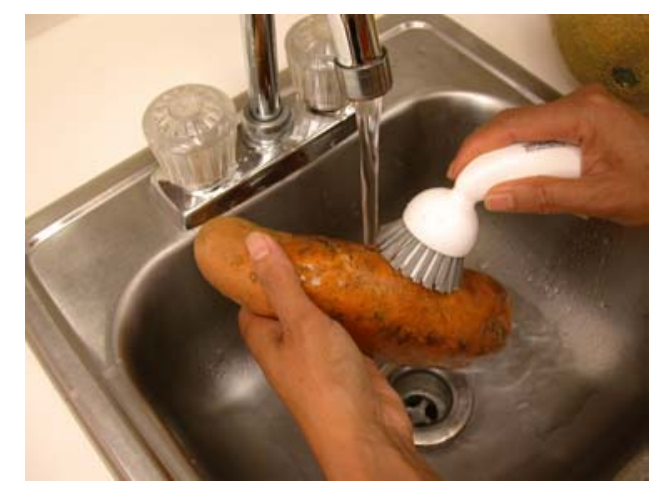

- Pay particular attention to underground vegetables that are consumed raw.

- Cut away bruised or damaged areas before preparing or eating.

- Wash cutting boards, dishes, utensils, and counter tops often. Use hot, soapy water and rinse well. Sanitize them after contact with fresh produce, or raw meat, poultry, or seafood (see box).

- Sanitize kitchen sink frequently to prevent a build up of microbes.

- Do not cross contaminate!

- Use clean cutting boards and utensils for fresh produce.

- Do not mix unwashed underground vegetables with other clean fruits and vegetables.
- If you can, use a separate cutting board for raw meat, poultry, and seafood. Always sanitize the cutting board before using it to prepare ready-to-eat foods.

- Do not consume ice that has come in contact with fresh produce or other raw products.

- Use a cooler with ice or ice gel packs when you take perishable foods outdoors. This includes cut fresh fruits and vegetables.

\section{To Sanitize}

- Mix one teaspoon chlorine bleach in one quart water.

- Pour the mixture onto the surface and let it sit at least one minute.

- Rinse well with hot running water.

Following these step will help reduce your risk of foodborne illness from fresh produce.

\section{For more information}

you can visit the Food and Drug

Administration (FDA) website at:

http://www.fda.gov

or call FDA Consumer Inquiries at 1-888-

SAFEFOOD (a toll-free number). 